\title{
A IMPORTÂNCIA DOS ESPAÇOS PÚBLICOS E ÁREAS VERDES PÓS- PANDEMIA NA CIDADE DE SÃO PAULO (SP)
}

\author{
Deize Sbarai Sanches Ximenes \\ Gérsica Moraes Nogueira da Silva \\ Ivan Carlos Maglio \\ Júlio Barboza Chiquetto \\ Luís Fernando Amato-Lourenco \\ Maria da Penha Vasconcellos \\ Pedro Roberto Jacobi \\ Sonia Maria Viggiani Coutinho \\ Vivian Aparecida Blaso Souza Soares César
}

\section{RESUMO}

As cidades estão sofrendo profundas transformações no campo da saúde, cultura, relações sociais, e principalmente na vida urbana, provocando inúmeras reflexões e questionamentos ao modelo de cidade que poderá ser desfrutada pós-pandemia da COVID-19, destacando a importância e o papel dos espaços públicos e das áreas verdes em períodos excepcionais como no caso da pandemia e para o futuro da vida urbana. Diante da atual situação, este artigo tem por objetivo recomendar diretrizes de convivência e de uso adequado para as áreas verdes e espaços públicos, compatíveis com as exigências da saúde pública para o período da pandemia, até que se tenha uma vacina eficiente, e ao mesmo tempo, colaborar com diretrizes para uma qualidade de vida urbana com maior valorização das áreas verdes, vencida a pandemia. Esse estudo foi baseado na Pesquisa Emoções Momentâneas: Comportamentos e Hábitos Cotidianos Pós-Pandemia (XIMENES et al., 2020), nas revisões de literatura técnica e científica, nas análises das informações disponíveis e no mapeamento das áreas verdes do município de São Paulo. A ressignificação das cidades pós-pandemia deverá abordar a implementação de novas políticas públicas, e meios de apropriação e convivência dos espaços públicos, parques e áreas verdes da cidade de São Paulo, tornando-os mais humanizados, seguros e inclusivos; trabalhando estratégias integradas ao desenvolvimento urbano sustentável na retomada das atividades de lazer, cultura, gastronomia e entretenimento.

\section{Palavras-chave}

Vida urbana. Espaços públicos. Áreas verdes. Pós-pandemia. Pandemia da COVID-19. Cidade de São Paulo. 


\title{
THE IMPORTANCE OF PUBLIC SPACES AND GREEN AREAS IN THE POST-PANDEMIC IN THE CITY OF SÃO PAULO-SP
}

\author{
Deize Sbarai Sanches Ximenes \\ Gérsica Moraes Nogueira da Silva \\ Ivan Carlos Maglio \\ Júlio Barboza Chiquetto \\ Luís Fernando Amato-Lourenco \\ Maria da Penha Vasconcellos \\ Pedro Roberto Jacobi \\ Sonia Maria Viggiani Coutinho \\ Vivian Aparecida Blaso Souza Soares César
}

\begin{abstract}
Cities are undergoing profound transformations in the fields of health, culture, social relations, and especially in urban life, causing numerous reflections and questions to the city model that can be enjoyed after the pandemic of COVID-19, highlighting the importance and the role of public spaces and green areas in exceptional periods as in the case of the pandemic and for the future of urban life. In view of the situation, this article aims to recommend guidelines for coexistence and proper use of green areas and public spaces, compatible with public health requirements for the pandemic period, until an efficient vaccine is obtained, and, at the same time, collaborate with guidelines for the quality of urban life with greater appreciation of green areas after the pandemic is over. This study was based on the Momentary Emotions Research: Post-Pandemic Behaviors and Daily Habits (XIMENES et al., 2020), on the reviews of technical and scientific literature, on the analysis of the available information and on the mapping of the green areas in the city of São Paulo. The resignification of post-pandemic cities should address the implementation of new public policies, and means of appropriation and coexistence of public spaces, parks and green areas in the city of São Paulo. This will make them more humanized, safe and inclusive; development strategies integraded to sustainable urban development in the return of leisure, culture, gastronomy and entertainment activities.
\end{abstract}

\section{Keywords}

Urban life. Public spaces. Green areas. Post-pandemic. COVID-19 pandemic. São Paulo city. 


\section{INTRODUÇÃO}

O período de pandemia da COVID-19 impôs inúmeras transformações nas cidades no campo da política, economia, ambiente, cultura, relações sociais e afetivas, e para a vida urbana trazendo inúmeras reflexões e questionamentos sobre o modelo de cidade que queremos viver num possível futuro pós-pandemia.

Em dezembro de 2019, com a propagação do novo coronavírus SARS-CoV-2, causador da doença COVID-19 pelo mundo, as cidades adotaram novas medidas de saneamento e de combate à proliferação do vírus, reduzindo as atividades sociais, como comércio, lazer, cultura e serviços, assim como, o fechamento de parques e praças para não haver aglomerações. No Brasil, não foi diferente, após o primeiro caso de contaminação em fevereiro de 2020, que se alastrou pelos Estados por meio de transmissão comunitária; ocorrência de casos sem vínculo a um caso confirmado, em área definida, onde não é possível rastrear qual a origem da infecção, independente de terem viajado ou não para o exterior; seguiu as orientações da Organização Mundial da Saúde (OMS) para prevenção da COVID-19.

Com a disseminação do vírus causador da COVID-19, os espaços públicos foram transformados em um não-lugar. De acordo com Augé (1994), o lugar precisa ter uso e atividades, algum nível de relação emocional e características simbólicas suficientes. Uma cidade, um lugar, sem suas atividades, e principalmente com ausência da cultura, espaços público e pessoas, não é um lugar.

A pandemia do coronavírus está alterando profundamente a dinâmica da vida urbana em todas as cidades, em especial a dinâmica das metrópoles mundiais. É necessária uma reflexão sobre a forma como serão apropriados os espaços públicos e áreas verdes da cidade de São Paulo de forma segura, inclusiva e com qualidade de vida no pós-pandemia.

Para Gehl (2013), a vitalidade das cidades está na apropriação e uso do espaço público, ressaltando a importância de resgatar a dimensão humana das cidades para acomodar as pessoas em espaços públicos suficientes e projetados na escala humana, de forma agradável, segura, sustentável e saudável. Reforça-se a ideia de cidades vivas, nas quais as pessoas se sintam convidadas a permear os espaços públicos e a manter uma conexão destes com suas atividades cotidianas. São os bens comuns mais valiosos para a saúde e bem-estar das pessoas, por serem locais de encontro, de relações de afeto, e de estímulo dos laços comunitários.

A ONU-HABITAT (2016) reconhece que onde o espaço público é inadequado, negligenciado ou mal concebido, a cidade se torna cada vez mais segregadora. O planejamento e desenho adequado dos espaços públicos fortalecem o direito das pessoas de usufruir de espaços in- 
clusivos, seguros e acessíveis. Melhorar o acesso e a participação das pessoas mais vulneráveis é uma ferramenta poderosa na ressignificação das cidades pós-pandemia, sendo uma forma de reduzir as desigualdades e promover benefícios sociais e econômicos à essa população em áreas periféricas. Lefebvre (2013) evidencia a importância da homogeneidade e da globalização do espaço público em contraposição ao espaço fragmentado e hierárquico imposto por interesses econômicos, e por uma produção racional.

Embora as cidades compactas e com maior densidade e verticalização, no contexto do debate das mudanças climáticas, sejam preferíveis para a economia e eficiência no consumo de recursos e na mitigação dos impactos das mudanças climáticas (CALDAS et al., 2020), a pandemia da COVID-19 trouxe questionamentos sobre as cidades com altas densidades, colocando em cheque a densidade das cidades como um "inimigo", a partir dos casos em Wuhan, China, onde o vírus teve seu alastramento inicial. Embora a alta densidade tenha sido um aspecto observado inicialmente, as análises estatísticas não mostram uma conexão consistente entre a densidade das grandes cidades e os impactos do coronavírus. Alguns dos espaços mais povoados do mundo - Hong Kong, Seul, Cingapura - provaram ser os mais eficientes para conter a COVID-19. Nos EUA, pequenas cidades da Geórgia e Louisiana sofrem junto com a grande e densa cidade de Nova York (KLING, 2020).

Que lições podemos tirar da pandemia? As respostas a essa questão vão depender de como diagnosticamos o problema. Se não considerarmos as desigualdades e a exclusão social e territorial sistêmica, presentes no contexto urbano brasileiro, e que tornam certos lugares e populações mais vulneráveis, vamos voltar a culpabilizar a cidade como a "inimiga".

No século XVIII, a relação entre a pobreza e a mortalidade já começava a ser percebida na Europa, mas foi somente na primeira metade do século XIX que se desenvolveram, de maneira sistemática, as investigações sobre as relações entre o processo saúde-doença e as profundas desigualdades sociais. O impacto da Revolução Industrial sobre as condições de vida dos habitantes das cidades europeias, agravou um quadro sanitário, impulsionando estudos epidemiológicos sobre as precárias condições de vida e suas consequências (SILVA; BARROS; 2002).

$\mathrm{Na}$ década de 1990, os estudos acadêmicos sobre desigualdades sociais em saúde obtiveram um grande avanço com o desenvolvimento de métodos de análise; de novas técnicas de mensuração de disparidades; assim como conhecimentos anteriormente adquiridos sobre as principais pandemias, aprofundando as análises de mortes em camadas mais vulneráveis (SILVA; BARROS; 2002).

Mas se considerarmos, que as cidades podem concentrar mais facilmente recursos e serviços sociais, com acesso mais rápido aos hospitais 
1. O decrescimento sereno proposto por Serge Latouche indica que é preciso rever padrões de produção e consumo a partir da perspectiva que temos de um planeta com recursos finitos e que não suportaria sobreviver aos padrões de produção e consumo mundiais de forma exponencial. "Entende-se implícita ou explicitamente a necessidade de voltar a um nível de produção sustentável, compatível com a reprodução dos ecossistemas" (Latouche, 2009, pág. 47). e cuidados de saúde (KLING, 2020), quando alimentadas pela infraestrutura social - centros comunitários, bibliotecas e, sim, espaços e parques públicos - as cidades podem gerar redes de vínculos sociais que salvam vidas, que combatem o isolamento e atenuam os efeitos de desastres. Nesse sentido, é importante investir em medidas que reduzam a vulnerabilidade social e ambiental, que ampliem os espaços públicos e as áreas verdes para maior equidade e qualificação da vida urbana.

Como preocupação central do presente artigo, a fruição, a permanência e o convívio das pessoas nos espaços públicos só será possível durante a pandemia quando se sentirem seguras e acolhidas, se respeitarem regras mútuas de segurança sanitária, tais como: limitações de acesso, limitação do número de pessoas por área do espaço público, manutenção de distâncias de segurança, uso de máscaras, higienização das mãos, entre outras.

Nesse sentido, um dos objetivos deste artigo é recomendar diretrizes de convivência e de uso adequado para as áreas verdes e espaços públicos, compatíveis com as exigências da saúde pública apoiadas por estudos científicos, até que se tenha uma vacina eficiente para a doença e afastados os riscos de sua propagação ampliados pela concentração de pessoas. Ao mesmo tempo, o grande desafio e a oportunidade que se coloca é o de repensar a vida urbana, vencida a pandemia, estimulando novos paradigmas, influenciando políticas públicas, e com novos hábitos e opções sustentáveis que contribuam em tornar as cidades mais inclusivas, saudáveis e seguras, com maior valorização das áreas verdes e espaços públicos, especialmente os abertos, destinados a inúmeras atividades e propósitos, como lazer, saúde e cultura.

O desafio para o planejamento das cidades seria a cocriação de estratégias integradas entre desenvolvimento e decrescimento sereno, conceito abordado por Latouche (2009) ${ }^{1}$ para cooperar com a recuperação da degradação ambiental e com a redução de impactos socioeconômicos, que dialoguem com iniciativas locais e globais visando o urbanismo sustentável. Por outro lado, o enfrentamento emergencial da pandemia da COVID-19, não soluciona e realça os problemas pré-existentes relacionados à desigualdade social, e a vulnerabilidade socioambiental das cidades aos impactos climáticos, no qual as áreas verdes cumprem papéis e funções ambientais fundamentais na ampliação da resiliência urbana.

Acredita-se que com o efeito da pandemia, o comportamento das pessoas irá se transformar, e os cuidados com a saúde e o bem-estar deverão se intensificar, surgindo novas tendências no uso e na escolha de espaços de convivência, podendo optar por espaços públicos ao ar livre, como praças, parques e áreas verdes, ou os espaços confinados, como shoppings, museus, galerias, entre outros, necessitando que nessas situações, as atividades possam ser reiniciadas de forma 
segura, com o uso adequado pela população e evitando aglomeração inadequada aos novos padrões de saúde pública.

Recente pesquisa, aplicada em maio de 2020 por pesquisadores do Programa Cidades Globais do Instituto de Estudos Avançados da Universidade de São Paulo, levantou a percepção de brasileiros sobre seu comportamento e hábitos cotidianos com o controle da pandemia e em um cenário futuro pós-pandemia, com 1956 respondentes. Entre os resultados, que são emoções momentâneas, indica-se que o contato com outras pessoas e com a natureza são os fatores que mais têm feito falta durante o isolamento social, com $86 \%$ das pessoas indicando a falta de estarem junto às áreas verdes. Também, como veremos neste artigo, os resultados ainda mostram que poderá haver mudanças no comportamento das pessoas (XIMENES et al.,2020).

O objetivo do questionário citado, foi buscar elementos que sustentem recomendações de convivência e protocolos de uso adequados para a utilização das áreas verdes e espaços públicos durante e após a pandemia da COVID-19 e a percepção das pessoas sob suas aspirações para a vida urbana pós-pandemia.

Assim, considerando o atual período de pandemia que estamos vivendo, este artigo tem por objetivo recomendar diretrizes de convivência e de uso adequado para as áreas verdes e espaços públicos, compatíveis com as exigências da saúde pública para o período da pandemia, até que se tenha uma vacina eficiente para a doença e afastados os riscos de sua propagação ampliados pela concentração de pessoas; e ao mesmo tempo, influenciar políticas públicas e estimular novos hábitos e comportamentos, com maior valorização das áreas verdes e espaços públicos, para uma ressignificação da vida urbana pós-pandemia.

\section{METODOLOGIA}

A metodologia utilizada para o presente trabalho baseia-se na pesquisa de opinião realizada por pesquisadores do Programa Cidades Globais do IEA USP (XIMENES et al, 2020) citada anteriormente, onde obteve como resultados a falta das áreas verdes durante o distanciamento social, e a indicação de praças como locais de maior frequência no pós COVID-19, por 90,5\% dos respondentes, fortalecendo a recomendação para ampliação das áreas verdes públicas. Confirma-se, portanto, a importância das áreas verdes públicas apontada na literatura (AMANO; BUTT; PEH, 2018; AMATO-LOURENÇO et al., 2016; THOMPSON et al., 2016; TAKANO, 2002;).

No caso do município de São Paulo utilizou-se o monitoramento dos indicadores de áreas verdes por habitantes nos distritos e bairros, para 
a definição de metas a serem atingidas. Essas metas deverão considerar a ampliação do índice de áreas verdes de forma equilibrada entre os distritos municipais, visando reduzir as desigualdades existentes na distribuição das áreas verdes no município de São Paulo. Para tal, acompanha-se com atenção a elaboração do Plano Municipal de Áreas Protegidas, Áreas Verdes e Espaços Livres (PLANPAVEL) em elaboração pela Prefeitura Municipal de São Paulo.

A partir da pesquisa de opinião, da leitura de mapas e análise de dados produzidos pela Prefeitura de São Paulo, com relação a quantidade e distribuição das áreas verdes do município e o potencial de cobertura vegetal existente, a pesquisa de percepção fornece uma série de evidências e constatações que subsidiaram a formulação de recomendações para espaços livres vegetados durante e após a pandemia. Dessa forma, algumas sugestões de políticas públicas e de novos hábitos e comportamentos foram apresentadas para subsidiar esses protocolos de uso dos espaços públicos.

\section{DISCUSSÃO E RESULTADOS}

O espaço público molda a imagem da cidade e sua apropriação por parte da população, desde grandes parques urbanos a jardins de bairros, potencializando a necessidade de áreas verdes, e assumindo diferentes formas espaciais incluindo ruas, calçadas, caminhos, parques, becos; uma rede de espaços que fortalece as conexões entre pessoas e cria a vida urbana.

Em seu livro "The Death And Life of Great American Cities", Jacobs (1961) já abordava uma clara definição do espaço público tão inovadora para sua época, defendendo a vitalidade e o frequente movimento das ruas e dos espaços verdes. Os espaços públicos com quadras de tamanho padrão, edifícios com visão das calçadas, esquinas e cruzamentos abertos ao olhar do transeunte são áreas vitais na cultura urbana segura. Jacobs sempre foi uma grande defensora da vida urbana, trazendo como aliadas a densidade e a vida em comunidade; pontos elementares para a qualidade de vida.

De forma semelhante, Whyte (1980) dedicou grande parte da sua vida aos estudos da vida urbana, enfatizando os elementos essenciais que um espaço público deveria contemplar para atrair pessoas e se tornar o lugar de convivência e de vida. Ele acreditava que temos uma responsabilidade moral de criar lugares físicos que facilitem o envolvimento cívico e a interação com a comunidade. Um exemplo foi o fechamento oficial para veículos da principal avenida de São Paulo aos domingos e feriados - a Avenida Paulista, pelo Decreto n 57.086 (24/06/2016) instituindo oficialmente o Programa Ruas Abertas nos termos da Política 
Nacional de Mobilidade Urbana, colocando-a como um grande espaço público, ponto de encontro democrático dos paulistanos e visitantes e um espaço pontuado por centros culturais, facilidades de transporte público e acesso por ciclovias.

No início do século $X X$, a criação dos parques urbanos se fortalece num cenário de cidades industrializadas, onde Frederick Law Olmsted ${ }^{2}$ afirma que a quantidade de doenças, vícios e crimes, só seria combatida com o pensamento ambiental, trazendo o ar puro desinfectado pela luz solar e pelas árvores; sendo essas definidas por ele como os "pulmões" da cidade. Os parques urbanos trariam um conforto à vida urbana levando à população acomodações agradáveis e acessíveis, com espaços recreativos que garantiriam um estado de espírito bemhumorado e saudável. Via a vida urbana como uma ameaça à saúde física e mental das pessoas e estimulava à contemplação de paisagens naturais que pudessem amenizar a estrutura urbana adensada com funções saneadoras, representando oásis de ar puro, contemplação e alívio da rotina e afazeres da vida urbana (OLMSTED, 1997).

2. Frederick Law Olmsted (18221903) arquiteto paisagista, foi o mais legítimo tradutor do pensamento ambientalista para o projeto de paisagismo no final do século XIX, nos EUA. Projetou importantes parques urbanos, como o Central Park (Nova lorque) e o Emerald Necklace (Boston). É considerado o pai da arquitetura da paisagem americana..

3. São Paulo, Plano Diretor Estratégico - PDE 2014, Art. 265. O Sistema de Áreas Protegidas, Áreas Verdes e Espaços Livres é constituído pelo conjunto de áreas enquadradas nas diversas categorias protegidas pela legislação ambiental, de terras indígenas, de áreas prestadoras de serviços ambientais, das diversas tipologias de parques de logradouros públicos, de espaços vegetados e de espaços não ocupados por edificações cobertas, de propriedade pública ou particular.

\section{As áreas verdes nas grandes metrópoles: a cidade de São Paulo como estudo de caso}

Para avaliar as possibilidades da população urbana paulistana usufruir das áreas verdes e dos seus benefícios durante e após a pandemia, realizou-se a análise da relação de área verde por habitante, que demonstrou um grande desequilíbrio na sua distribuição entre a periferia e o centro, ou seja, entre as regiões mais carentes e as mais valorizadas, evidenciando a desigualdade social em relação ao acesso a parques e praças.

O total de áreas verdes consolidadas para o cálculo dos indicadores per capita, no caso do município de São $\mathrm{Paulo}^{3}$, têm origem nas seguintes tipologias: áreas mapeadas nas UCs presentes no território e áreas verdes públicas presentes em parques e praças municipais.

Constatou-se que São Paulo tem carência de espaços livres públicos de áreas verdes, e que as normas de proteção ambiental em todos os níveis governamentais, fortalecidas a partir da Lei da Política Nacional de Meio Ambiente de 1981 (Lei 6938/81), levaram à conservação de extensos territórios localizados principalmente no extremo norte e ao sul da cidade que não se destinaram ao processo de urbanização. Esses espaços se encontram na periferia da cidade sob pressão dos vetores de expansão urbana, mas também estão presentes em muito menor dimensão e de forma fragmentária nos espaços mais centrais da cidade ou nos seus bairros já consolidados. Nesses casos são pequenos fragmentos de Mata Atlântica isolados e trechos em margens de corpos d'água que ainda possuem funções naturais e são capazes de oferecer oportunidades de melhoramento ambiental de todo o conjunto urbano da cidade. 
4. O Sistema Nacional de Unidades de Conservação (SNUC - LEI 9.985/2000) é o conjunto de unidades de conservação (UC) federais, estaduais e municipais. É composto por 12 categorias de UC, cujos objetivos específicos se diferenciam quanto à forma de proteção e usos permitidos: aquelas que precisam de maiores cuidados, pela sua fragilidade e particularidades, e aquelas que podem ser utilizadas de forma sustentável e conservadas ao mesmo tempo. In: https://www. mma.gov.br/areas-protegidas/ unidades-de-conservacao/sistemanacional-de-ucs-snuc.html (consulta em 25/05/2020).
Segundo o Plano Municipal de Conservação e Restauração da Mata Atlântica (PMMA, SÃO PAULO, 2017), distribuídas conforme descrito acima, cerca de $30 \%$ da área do município de São Paulo ainda estão cobertas por este bioma, um dos mais ricos em biodiversidade do mundo e um dos mais ameaçados.

Segundo a SVMA (2020), a cidade de São Paulo possui cerca de 40.000 hectares protegidos através de nove Unidades de Conservação municipais duas do grupo de Uso Sustentável (Áreas de Proteção Ambiental APAS) e sete de Proteção Integral (Parques Naturais Municipais - PNMs) e um Refúgio de Vida Silvestre - RVS. Os parques municipais e estaduais urbanos e os parques considerados unidades de conservação estaduais e municipais em território paulistano regulamentadas até o momento podem ser vistas a seguir (Figura 1). Essas categorias estão definidas segundo o Sistema Nacional de Unidades de Conservação ${ }^{4}$ (SNUC - LEI 9.985/2000).

Esses números dão a dimensão das quantidades de áreas em destaque da proteção e manejo de acordo com os objetivos estabelecidas no SNUC (Sistema Nacional de Unidades de Conservação) e da importância estratégica dos remanescentes protegidos dos recursos ecossistêmicos do município de São Paulo.

As áreas verdes urbanas desempenham diversas funções básicas relacionadas ao ecossistema e ao bem-estar dos habitantes na cidade (GRANDE-ORTIZ et al., 2012). No âmbito dos serviços ecossistêmicos, destacam-se outros aspectos importantes das áreas verdes para o meio ambiente urbano, como a regulação do clima, da qualidade do ar, o armazenamento do carbono, o provimento de água, a proteção da biodiversidade e a beleza cênica, influenciando positivamente na saúde e na qualidade de vida da população (PAULEIT et al., 2000; NOWAK et al., 2007; DAVIES et al., 2011). Sob este prisma, é possível constatar que os benefícios de saúde e serviços ecossistêmicos das áreas verdes são reconhecidos mundialmente.

Segundo Buckeridge (2015), as árvores urbanas podem trazer muitos benefícios para a saúde humana, entre os quais pode-se citar, conforme estudo conduzido por Nowak e Dwyer (2007) com modelagens feitas para dez cidades americanas, a capacidade de remover da atmosfera material particulado em grandes quantidades. Os autores afirmam que, de acordo com o modelo, somente em Nova York, a retirada desse tipo de material teria levado a uma economia de US\$60,1 milhões e teria evitado a morte de 7,6 habitantes em um ano.

Há também benefícios menos palpáveis, mas não menos desprezíveis, da presença das árvores no meio urbano. Pesquisas mostram que pessoas que vivem em cidades arborizadas têm menor tendência ao estresse e à depressão (GILCHRIST, 2015). 


\section{FIGURA 1.}

Mapa das Unidades de Conservação Estaduais e Municipais situadas no município de São Paulo. Fonte: Elaborado por Juliana Colli Munhoz com base no PMSP, SMDU (PDE, 2014) e SVMA (2016), 2020.

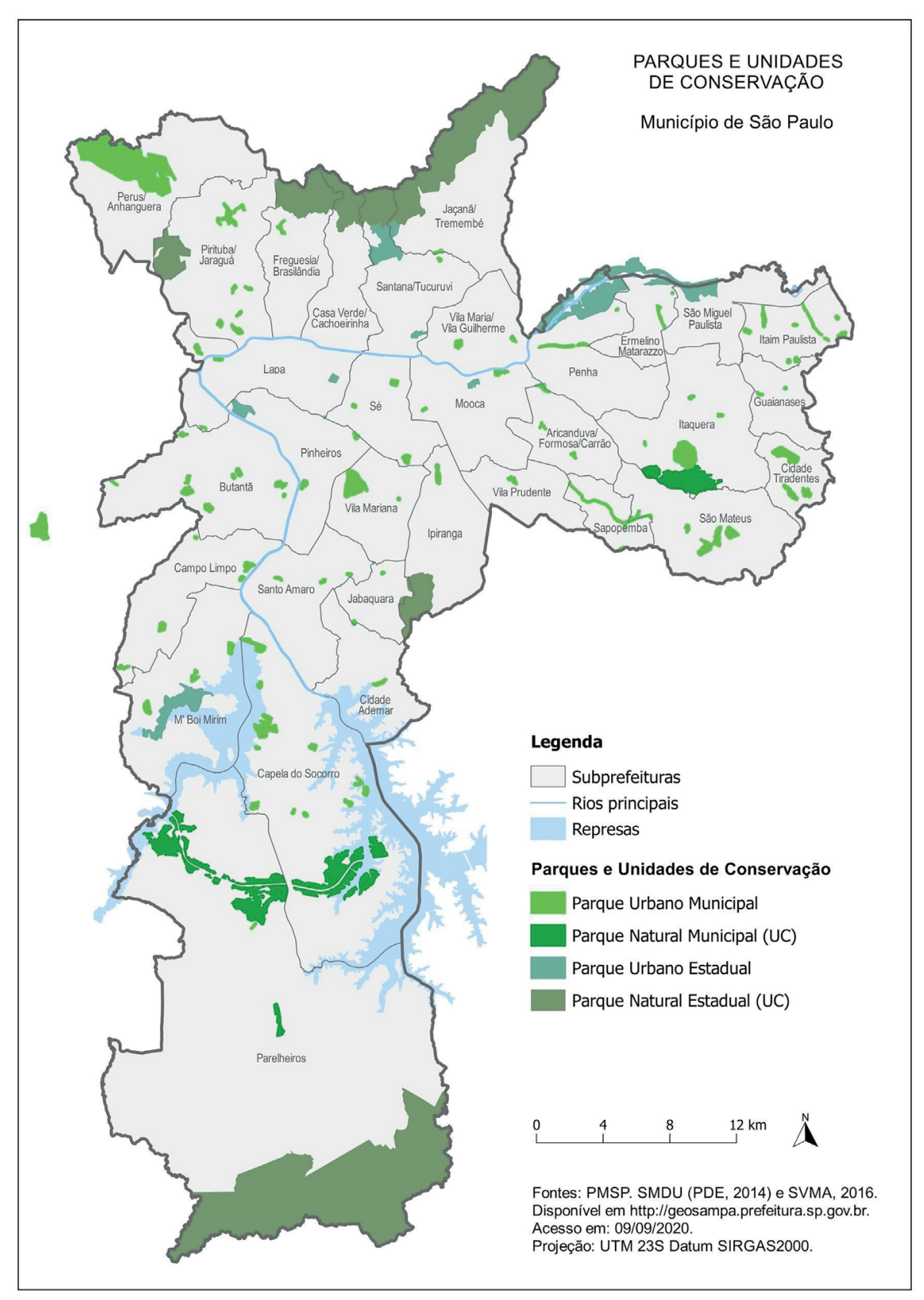

Embora seja reconhecida a importância da cobertura vegetal para as cidades, principalmente para os grandes centros urbanos, não há engajamento ou comprometimento suficientes para deter a degradação ambiental urbana em curso ou tentar reverter seus efeitos prejudiciais à saúde humana, em primeiro lugar (TEEB, 2011).

A título de comparação, o município de Campinas no Estado de São Paulo considerou como um parâmetro relevante na elaboração do seu Plano Municipal do Verde (2016), a questão das distâncias mínimas a serem percorridas no interior do território municipal para que os habitantes possam acessar e utilizar as áreas verdes públicas mais próximas e a adoção dos corredores ecológicos, como forma de conectividade de fragmentos vegetais (CAMPINAS, 2016), trazendo como 
5. A Subprefeitura de Parelheiros apresenta um indicador excepcionalmente alto, pois responde sozinha por cerca de $50 \%$ de toda a vegetação da cidade e tem baixíssima densidade demográfica.

6. A ONU (Organização das Nações Unidas), a FAO (Organização de Alimentação e Agricultura) e a OMS (Organização Mundial de Saúde) recomendam que as cidades devam dispor de no mínimo $12 \mathrm{~m}^{2}$ de cobertura vegetal/habitante, considerando um valor ideal para melhoria da qualidade de vida da população. (Cavalheiro e Del Picchia,1992 apud Harder et al 2006). citação em seu plano, os chamados "Green Plan" - desenvolvido por diversos países fora do Brasil com o intuito de desenvolver planos voltados à restauração do meio ambiente.

Em relação às áreas verdes públicas em conjunto com as unidades de conservação, a cidade de São Paulo, segundo dados da Secretaria Municipal do Verde e do Meio Ambiente (SÃO PAULO, 2017), perfazem $16,59 \mathrm{~m}^{2}$ de área verde/hab. no geral (Figura 2). Isso se deve, em grande parte, ao Parque Estadual da Cantareira localizado no extremo norte do município (Subprefeituras de Jaçanã/Tremembé e Perus principalmente) e ao Parque Estadual da Serra do Mar, localizado no extremo sul do município (Distrito de Parelheiros). Estas áreas verdes, apesar de se localizarem em regiões periféricas, não são acessíveis à população, devido ao status de unidade de conservação. Algumas delas possuem uso restrito, e na maioria dos casos, não estão integradas em uma rede de transportes à comunidade; porém se retirarmos essas três Subprefeituras (Tremembé-Jaçanã, Perus e Parelheiros) onde se concentram as UCs de maior porte, a média de áreas verdes por habitante municipal cai para 7,095 $\mathrm{m}^{2} / \mathrm{hab}$.

A subprefeitura de Parelheiros ${ }^{5}$ concentra cerca de $49 \%$ do total de áreas verdes no município, em contraponto aos $11 \%$ totalizados nas 12 subprefeituras da zona leste da cidade (SÃO PAULO, 2017).

Buckeridge (2015) também observou a questão da má distribuição das áreas verdes na cidade de São Paulo. Utilizou o Índice de Cobertura Vegetal (ICV) elaborado pela Secretaria Municipal do Verde e do Meio Ambiente em 2012 e considerou os valores de área de cobertura vegetal pelo número de habitantes em cada região administrativa. Observou que em algumas regiões periféricas apresentam altos valores de ICV, claramente afetadas pela existência de resíduos de florestas ou parques estaduais próximos à cidade, e que o centro e a região leste da cidade se apresentam como zonas com ICV muito baixos da ordem de 2 a $6 \mathrm{~m}^{2}$ de área verde por habitante (SÃO PAULO, 2012).

Esta análise resultou na elaboração do Mapa Índice de Áreas Verdes públicas por habitante (Figura 2) calculado a partir dos dados de população em 2010 e da quantidade de áreas verdes públicas em 2017 (incluindo áreas verdes e unidades de conservação parques naturais) por Subprefeitura do Município de São Paulo.

De acordo com a Figura 2, pode-se verificar que a Subprefeitura com o pior índice de área verde por habitante é Cidade Ademar (zona sul) com menos de $1 \mathrm{~m}^{2} /$ hab. , seguida de Guaianases, Vila Prudente, Sapopemba (zona leste) e Campo Limpo (zona sul) que apresentam indicadores muito baixos, entre 1 e $2 \mathrm{~m}^{2} / \mathrm{hab}$. Um pouco acima com índices que variam entre 2 e $5 \mathrm{~m}^{2} /$ hab., encontram-se as Subprefeituras da Sé, Mooca, Aricanduva/Vila Formosa, São Mateus, Cidade Tiradentes, Itaim Paulista, Ermelino Matarazzo, Vila Maria/Vila Guilherme, Vila Mariana, Jabaquara e Santo Amaro, totalizando 16 Subprefeituras que e apresentam índices abaixo de $5 \mathrm{~m}^{2} / \mathrm{hab}^{6}$ 
Outro aspecto fundamental, é um olhar especial para o uso correto dos parques urbanos, visto que, desde seu surgimento na Inglaterra, no final do século XVIII, já eram vistos como fundamentais à saúde pública; sendo muitas vezes criados sob conceitos estético-funcionais que pretendiam melhorar assentamentos humanos por razões sanitárias (MACEDO; SAKATA, 2010). Já no Brasil, com a intensificação do processo de urbanização a partir da década de 1950, os parques urbanos foram introduzidos com uma função ecológica, estética e de lazer, como forma de extensão das praças e jardins, localizados em áreas urbanas de uso público. Partindo da premissa das diferentes funções que os parques urbanos proporcionam à qualidade de vida, estes espaços abertos poderão voltar a ser frequentados pelas pessoas com uma redução gradual das medidas de isolamento social adotadas

FIGURA 2.

Índice de áreas verdes públicas por habitante no município de São Paulo. Fonte. Elaborado por Juliana Colli Munhoz com base na SVMA (2016), SMDU (PDE, 2014), IBGE (2017), 2020.

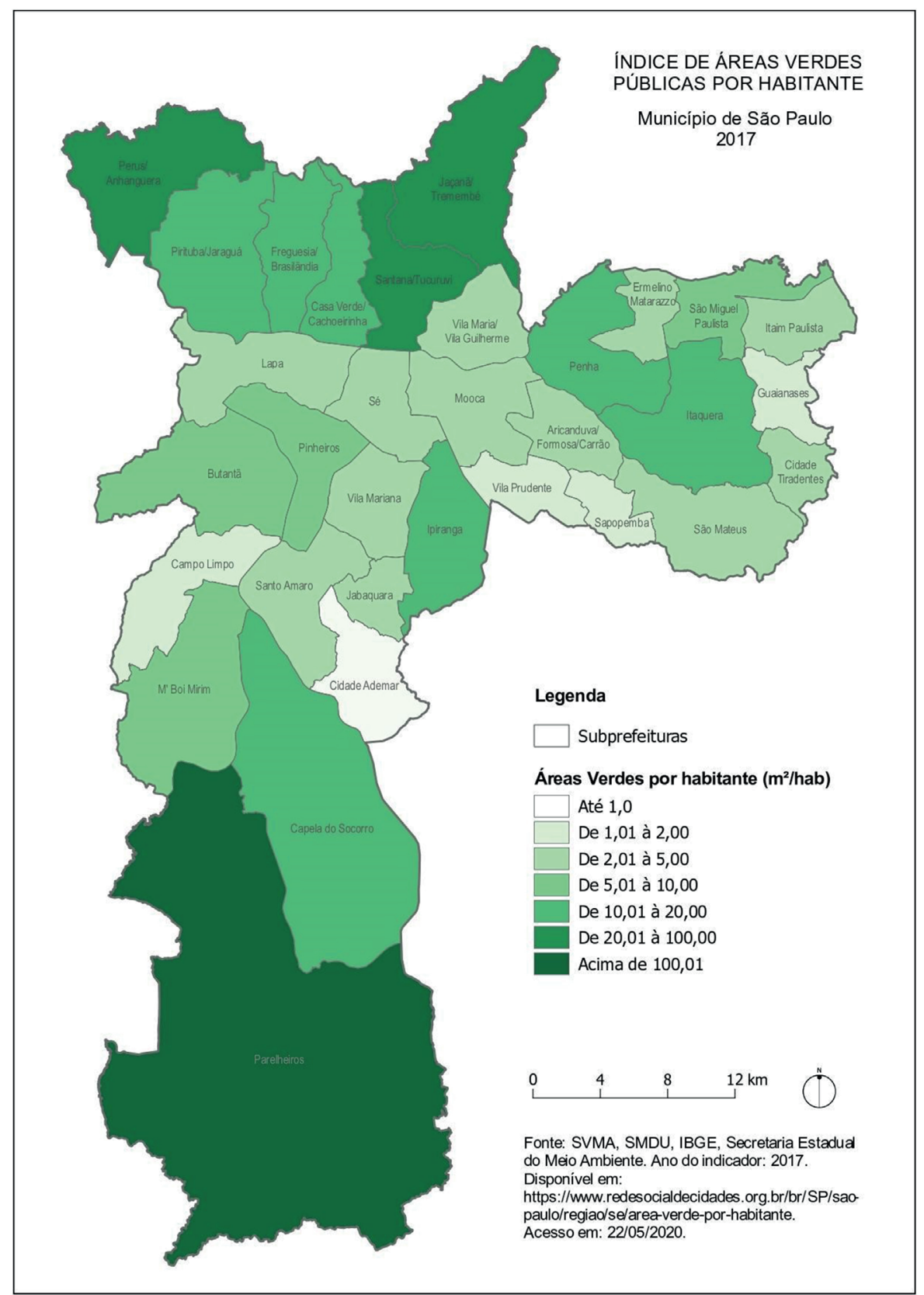


7. O protocolo para abertura dos parques municipais pode ser obtido em https://www. prefeitura. sp.gov.br/cidade/secretarias/meio_ ambiente/parques/programacao/ index. php? $p=300241$ ao longo da evolução do quadro pandêmico, considerando regras de distanciamento social e de não formação de aglomerações entre os frequentadores. A definição de limites para a capacidade de suporte de visitação e uso dos parques municipais e estaduais disponíveis no município de São Paulo, recomendada pela Prefeitura (SÃO PAULO, 2020a), gira em torno de $40 \%$ de sua capacidade, com vistas a formulação de diretrizes e propostas referentes ao padrão e a intensidade de uso desses territórios fundamentais para o convívio com a natureza e para a qualidade da vida urbana ${ }^{7}$.

Em países europeus, o número de pessoas que configuraram este limite para a capacidade suporte de utilização dos parques foi definido a partir do distanciamento social, ou seja, foi calculada uma distância mínima de 1,5 metros entre as pessoas, trazendo assim, uma referência para o cálculo de suporte para cada parque (área útil do parque/ distanciamento social mínimo = capacidade de suporte de utilização).

Sobrepondo os mapas de Unidades de Conservação Estaduais e Municipais e do Índice de áreas verdes públicas por habitante (Figuras 1 e 2, respectivamente), percebe-se a necessidade de um aumento expressivo na produção de áreas verdes e parques urbanos no município, uma vez que, como visto anteriormente, as maiores massas verdes se concentram nos extremos norte e sul da cidade.

Recentemente a prefeitura de São Paulo por meio da Secretaria Municipal do Verde e do Meio Ambiente, desenvolveu o mapeamento atualizado de toda a cobertura vegetal existente no município e o relatório "Cobertura Vegetal-Ranking Relativo". Ressalta-se que esse levantamento considerou todas as áreas cobertas com vegetação, sejam aquelas já transformadas em espaços públicos e UCs, mas também, toda a cobertura vegetal existente, que poderá contribuir para a ampliação do sistema de áreas verdes existentes e melhorar a atual situação de disponibilidade desses espaços para o uso público. (SÃO PAULO, 2020b)

Visando a análise da quantidade de área vegetada por subprefeitura, foi desenvolvido para este trabalho, o mapa da cobertura vegetal com dados atuais da Secretaria Municipal do Verde e do Meio Ambiente (SÃO PAULO, 2020), no qual observa que ainda há muitas oportunidades de ampliação das áreas verdes públicas (Figura 3). Tendo como exemplo, as Subprefeituras de São Mateus, Capela do Socorro, PareIheiros, Cidade Ademar, entre outras. Por outro lado, o detalhamento e a pesquisa da cobertura vegetal por distrito e em escalas territoriais menores (por bairros e quadras) poderá indicar novas oportunidades de criação de áreas verdes e parques municipais urbanos ou UCs, em especial nos territórios mais carentes destes espaços.

Neste item analisou-se a importância das áreas verdes e dos espaços públicos existentes e colocados à disposição para uso da população, na retomada gradual da vida urbana na cidade de São Paulo, após o 
FIGURA 3

Mapa de cobertura vegetal do município de São Paulo Fonte: Elaborado por Juliana Colli Munhoz com base na SVMA (2020) e GEOSAMPA (2020), 2020.

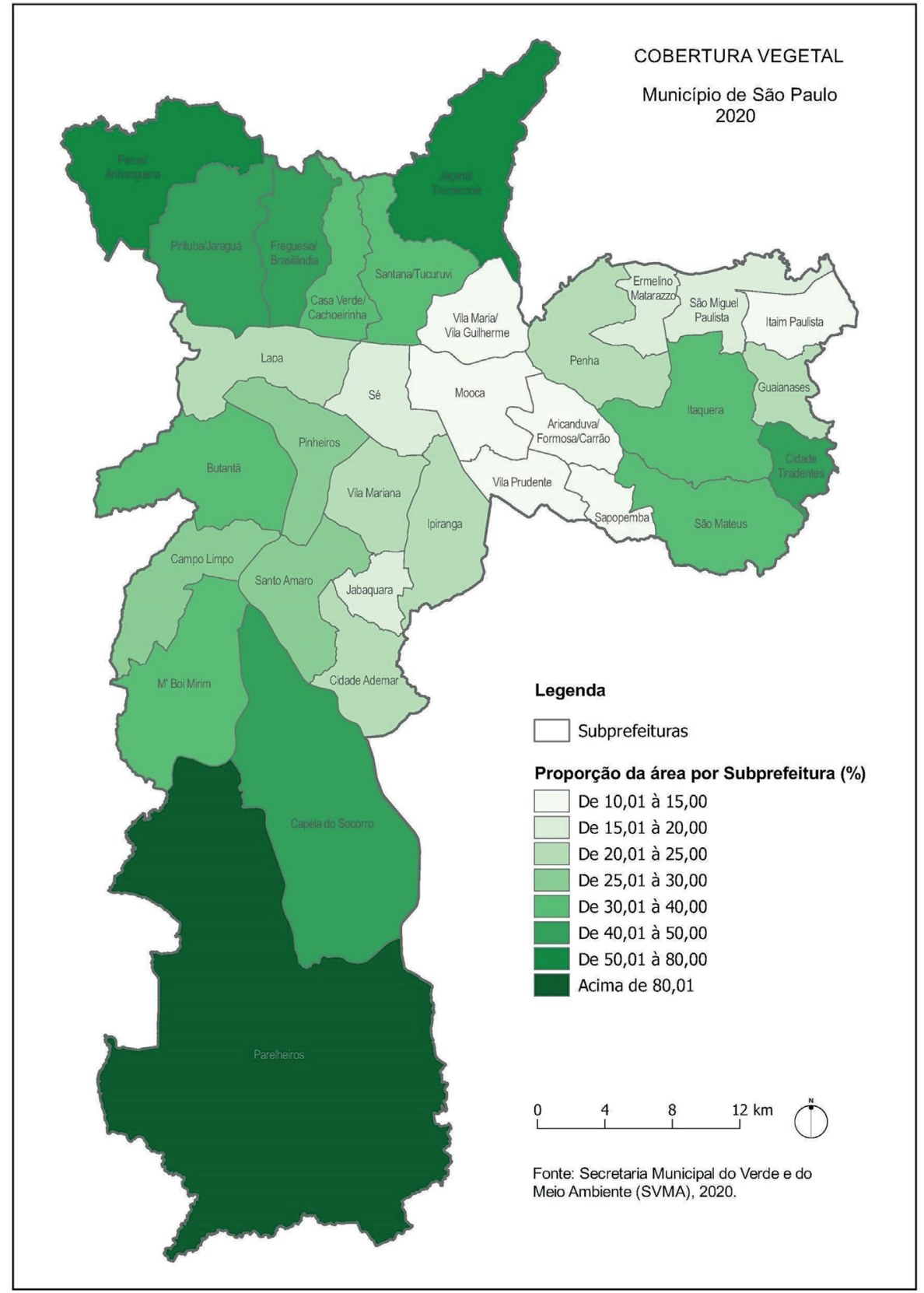

período mais crítico da pandemia. Demonstra-se a situação desigual de distribuição dessas áreas, indicando a necessidade emergencial de políticas públicas direcionadas a reduzir essa desigualdade de acesso a praças e parques, colocando-as a distâncias acessíveis e próximas às moradias. Por exemplo, no caso do Plano Municipal do Verde de Campinas (2016) considerou-se também como um parâmetro relevante, a questão das distâncias mínimas a serem percorridas no interior do território municipal, para que os habitantes pudessem acessar e utilizar as praças mais próximas.

A sensação de segurança das pessoas após a pandemia poderá ser maior em áreas próximas a suas casas, e em seus bairros, sem aglomerações de pessoas, levando à necessidade de criação de pontos de 
encontro, descentralizados e distribuídos. Também deverá se buscar maior equidade nas oportunidades de acesso a áreas verdes próximas, preferencialmente com acesso por transporte ativo ou a pé a diversas atividade que estes espaços propiciam - lazer, alimentação e compras.

O uso desses espaços existentes, por sua vez, deverá seguir procedimentos seguros, com o controle de permanência e evitando-se aglomerações, nas ruas, parques e praças. A acessibilidade deverá contar com a adequação do uso dos transportes públicos, assim como, o aumento no uso de bicicletas e do andar a pé. A permanência nestes espaços sem acarretar aglomerações, proporciona um ambiente saudável e seguro, a partir da adequação da capacidade suporte (em termos de número máximo de frequentadores por períodos) nos protocolos relacionados ao uso das áreas verdes e parques municipais durante e até que se tenha um maior controle da pandemia da COVID-19.

Recomenda-se também que sejam estabelecidas para o planejamento futuro no município condições para melhorar o Índice de Áreas Verdes por Subprefeituras, uma vez que embora o índice geral do município atinge atualmente de $16,59 \mathrm{~m}^{2} / \mathrm{hab}$. considerando-se as UCs e as praças, há 16 Subprefeituras, que apresentam índices abaixo de $5,0 \mathrm{~m}^{2} / \mathrm{hab}$., e também, outras subprefeituras periféricas que apresentam cobertura vegetal com áreas públicas de grande porte, e parte delas instituídas como unidades de conservação, apresentam índices muito acima dos recomendados, mas, ainda com dificuldades de acesso para o uso dessas unidades, que não estão ao alcance das populações locais. Casos de Subprefeituras de Parelheiros, Capela do Socorro, M'boi Mirim, Cidade Ademar no extremo sul do município, bem como, Perus/Anhanguera, Freguesia/ Brasilândia, Pirituba/Jaraguá, Jaçanã/Tremembé e Santana/Tucuruvi ao norte do município. Para tal, recomenda-se o planejamento de transportes públicos e programas de visitação organizados e programados para ampliar a visitação, dirigidos a diversas idades e públicos, considerando-se as novas regras saúde pública e respectivos protocolos a serem criados pelo município para enfrentar a pandemia da COVID-19.

Recomenda-se estudar uma regra que articule a ampliação desses indicadores de áreas verdes, por meio da destinação de recursos do Fundurb (Fundo de Desenvolvimento Urbano) para aplicação nas Subprefeituras com menores índices de praças e parque, visando um equilíbrio de forma geral no município e uma equidade de acesso a tais espaços.

Nas áreas periféricas é importante repensar a inclusão de pequenas praças e áreas verdes mais próximas das casas, assim como, a quantidade de árvores/bairro e seu distanciamento para obter espaços saudáveis e inclusivos. Outras recomendações poderão ser colocadas em prática como o uso dos vazios urbanos na escala do bairro com espaços públicos e áreas verdes como alternativa de esporte, lazer e 
cultura para as comunidades mais carentes. Também é recomendável repensar as formas de concessão das quase 5 mil praças existentes na cidade de São Paulo para dinamizar seu uso e conservação, aliando a presença de áreas verdes e espaços de convívio público. A atual forma de concessão parece pouco atrativa uma vez que menos de $10 \%$ desse total foi concedido nos moldes do Decreto 57.583 de 23 de janeiro de 2017 (SÃO PAULO, 2020b).

E por fim, trazer como uso alternativo, os espaços comuns das escolas públicas aos finais de semana, como local de lazer e convívio social da comunidade, a exemplo dos já implantados CEUs - Centros de Educação Unificados, a partir de 2002, que compõem atualmente uma rede com 46 unidades (SÃO PAULO, 2020c)

Portanto, além da equalizar a localização e a distribuição das áreas verdes e espaços públicos, deve-se pensar em outros aspectos como a legislação e a acessibilidade, para a devida integração destas áreas com os locais de moradia da população.

Repensar novas medidas de segurança sanitária para o uso adequado dos parques públicos da cidade de São Paulo durante e até o controle da pandemia da COVID-19 é extremamente importante, visto que são pontos importantes de concentração da população principalmente aos finais de semana. Medidas como a flexibilização do horário de funcionamento, com estabelecimento de horários alternativos que possam reduzir as aglomerações, a promoção de pontos de desinfecção, a disponibilização de álcool gel e lavatórios para a correta higienização das mãos, a capacitação dos funcionários dos parques para orientar a população do uso dos espaços livres de forma segura e com baixo risco de contágio, assim como, o cálculo de capacidade de suporte de cada parque, são fundamentais para o uso seguro desses espaços.

Nos espaços públicos utilizados com o fechamento de vias para pedestres, como no caso da Avenida Paulista, também deverá se utilizar os mesmos expedientes para evitar-se as aglomerações e a disponibilização de lugares para higienização e locais para controle e orientação da temperatura corporal.

Recomenda-se como uma base para a definição da capacidade de suporte para cada parque de São Paulo, uma distância de 1,5 metros entre as pessoas, trazendo assim, um cálculo com base no distanciamento e na área útil total do local (número de pessoas/área útil do parque).

A ampliação de áreas verdes disponíveis recoloca-se como medida ainda mais urgente nas metas municipais, promovendo a descentralização e a equidade no uso dos parques urbanos são medidas importantes numa situação pós-pandemia, onde a vazão ao fluxo de acesso possa ser controlada para não haver aglomerações e os ingressos possam ser distribuídos antecipadamente e on-line de acordo com a capacidade de suporte dos 
mesmos, como no caso do Jardim Zoológico e do Jardim Botânico.

Os deslocamentos na cidade durante e pós-pandemia para o acesso aos espaços públicos, praças e parques deverá ser reconfigurado, e novas propostas deverão ser implantadas tais como, a abertura de ruas para os pedestres nos finais de semana e o incentivo à criação de ciclovias e novas rotas para os ciclistas de forma segura e inclusiva. Estas medidas já estão sendo implantadas em cidades nos países europeus, onde a caminhada e o uso de bicicletas, além de evitarem a aglomeração no transporte público, contribuíram com a saúde das pessoas, reduzindo as comorbidades mais agravantes do coronavírus - pressão alta, obesidade e diabetes, e melhorias na qualidade de vida e na qualidade do ar com a redução dos poluentes atmosféricos.

Outras metas de mobilidade e deslocamento saudável poderão ser implantadas, como a redução do número de carros durante o dia, com horários alternativos de abertura do comércio e serviços, e estímulo a pequenos deslocamentos a pé para serviços essenciais do dia a dia, como mercados, farmácias, padarias, entre outros.

Em tempos de impactos socioeconômicos causados pela pandemia da COVID-19, as medidas de conscientização da população a novos hábitos e comportamentos nos espaços públicos, deverão ser arduamente divulgados por meios digitais ou tradicionais, mostrando a devida importância da seguridade; as medidas de comunicação visual e publicidade urbana previstas na Lei n 14.223 - Cidade limpa.

\section{CONCLUSÃO}

O enfrentamento da COVID-19 nos obriga a repensar: quais seriam as estratégias viáveis frente às novas normas, modelos de urbanização e políticas de convivências de uma vida em comum nas cidades.

Impactados pelo medo e incertezas de um futuro por vir, respostas urgentes necessitam ser pensadas. Por outro lado, a crise provocada pelo coronavírus é também uma oportunidade de reorientar a vida urbana para a superação da carência de áreas verdes e de espaços públicos que afeta as grandes cidades, a exemplo de São Paulo.

A reconexão do cidadão e as boas práticas comunitárias vêm demonstrando a força nas relações de solidariedade durante a COVID-19 espalhadas nas comunidades por meio da auto organização social, como vem ocorrendo na comunidade de Paraisópolis, na zona sudoeste de São Paulo. Essas iniciativas abrem brechas para imaginarmos como as relações afetivas entre a sociedade e a natureza podem ser recontextualizadas, em um novo modelo de urbanização inclusivo e solidário. 
A ética da comunidade do mundo globalizado, compreendida dentro da lógica dos movimentos de fraternidade, estão sendo tecidos porque o que está operando neste momento não é a lógica da sociedade, mas a lógica do nós - a lógica da comunidade, do pertencimento ao coletivo.

Com base no caso da cidade de São Paulo, percebe-se a necessidade de novas políticas públicas urbanas mais inclusivas que visem o reordenamento de uma nova lógica de organização econômica e social das cidades conforme apontado nas pesquisas realizadas até o momento. Tudo indica que será necessário reconstruir as lógicas de funcionamento das cidades atuais visando políticas e diretrizes para alcançarmos cidades conviviais, seguras e sustentáveis que integrem: normas e valores comportamentais priorizando a reorganização dos espaços públicos e semipúblicos integrados à infraestrutura verde, reforçando e dinamizando a rede hídrica e ambiental proposta no Plano Diretor Estratégico de 2014.

Por tratar-se de um vírus ainda em estudo e sem disponibilização de controle vacinal, esta trabalho elaborado durante a fase aguda da pandemia da COVID-19 em articulação com a Pesquisa Emoções Momentâneas Comportamentos e Hábitos Cotidianos Pós-pandemia e demais artigos científicos analisados, objetiva também contribuir para as diretrizes a serem elaboradas pelos gestores públicos na cidade de São Paulo, com a intenção de subsidiar protocolos adequados para reabertura e adaptações de uso de áreas públicas, que estimulem de forma segura e gradual a retomada das atividades, e simultaneamente, repensar a adequação dos espaços públicos com a inserção das áreas verdes na ressignificação de um modelo urbano pós-pandemia. 


\section{Deize Sbarai Sanches Ximenes}

Instituto Estudos Avançados - USP

deizesanches@usp.br | ORCID: https://orcid.org/0000-0002-0935-912X

\section{Gérsica Moraes Nogueira da Silva}

Instituto Estudos Avançados - USP

gersicamns@usp.br | ORCID: https://orcid.org/0000-0003-2043-5063

\section{Ivan Carlos Maglio}

Instituto Estudos Avançados - USP

ivmaglio@usp.br | ORCID: https://orcid.org/0000-0002-2665-2424

\section{Júlio Barboza Chiquetto}

Instituto Estudos Avançados - USP

julio22@gmail.com | ORCID: https://orcid.org/0000-0002-4013-7947

\section{Luís Fernando Amato-Lourenco}

Faculdade de Medicina/Instituto Estudos Avançados - USP

luisfamato@usp.br | ORCID: https://orcid.org/0000-0002-4015-6654

\section{Maria da Penha Vasconcellos}

Faculdade de Saúde Pública/Instituto Estudos Avançados - USP

mpvascon@usp.br | ORCID: https://orcid.org/0000-0003-2666-9485

\section{Pedro Roberto Jacobi}

Instituto de Energia e Ambiente/Instituto Estudos Avançados - USP

prjacobi@gmail.com | ORCID: https://orcid.org/0000-0001-6143-3019

\section{Sonia Maria Viggiani Coutinho}

Instituto de Energia e Ambiente/Instituto Estudos Avançados - USP scoutinho@usp.br|ORCID: https://orcid.org/0000-0001-8525-2562

\section{Vivian Aparecida Blaso Souza Soares César}

Instituto de Energia e Ambiente/Instituto Estudos Avançados - USP

vivianblaso@usp.br | ORCID: https://orcid.org/0000-0002-2348-3813

\section{Juliana Colli Munhoz}

Geógrafa, mestre em geografia e especiacialista em geoprocessamento.

Colaboração em cartografia digital 


\section{REFERÊNCIAS}

AMANO, Tatsuya; BUTT, Isabel; PEH, Kelvin S. H. The importance of green spaces to public health: a multi-continental analysis. Ecological Applications, [S.L.], v. 28, n. 6, p. 1473-1480, 20 jun. 2018. Wiley. http://dx.doi.org/10.1002/ eap. 1748 .

AMATO-LOURENÇO et al. Metrópoles, cobertura vegetal, áreas verdes e saúde. Estudos Avançados, [S.L.], v. 30, n. 86, p. 113-130, abr. 2016. FapUNIFESP (SciELO). http://dx.doi.org/10.1590/s0103-40142016.00100008.

AUGÉ, Marc. Não Lugares: Introdução a uma antropologia da supermodernidade. Campinas: Papirus, 1994.

BRASIL. Lei Federal n 9.985, de 18 de julho de 2000. Disponível em: <http://www.planalto.gov.br/ccivil/leis/L9985. htm>. Acesso em outubro/2020

BRASIL. Lei Federal n 6.938, de 31 de agosto de 1981. Disponível em: <http://www.planalto.gov.br/ccivil_03/leis/ 16938. htm>. Acesso em outubro/2020

BUCKERIDGE, Marcos. Árvores urbanas em São Paulo: planejamento, economia e água. Estudos Avançados, [S.L.], V. 29, n. 84, p. 85-101, ago. 2015. FapUNIFESP (SciELO). http://dx.doi.org/10.1590/s0103-40142015000200006

CALDAS, Lucas Rosse et al. Como tornar as cidades mais inteligentes diante das mudanças climáticas e pandemias? 2020. Disponível em: <https://www.archdaily.com.br/br/936764/como-tornar-as-cidades-mais-inteligentes-diante-das-mudancas-climaticas-e-pandemias $>$ Acesso em abril/2020.

CAMPINAS (cidade). Secretaria Municipal do Verde, Meio Ambiente e Desenvolvimento Sustentável. Plano Municipal do Verde. Prognósticos. 2016. Disponível em: <http://www.campinas.sp.gov.br/arquivos/meio-ambiente/vol-3-prognostico.pdf $>$ Acesso em outubro/2020.

CAVALHEIRO, Felisberto; DEL PICCHIA, Paulo Celso Dornelles. Áreas verdes: conceitos, objetivos e diretrizes para o planejamento. In: IV Encontro Nacional sobre Arborização Urbana, 1992, Vitória. Anais. Vitória, 1992, p. 29-38.

DAVIES, Zoe G. et al. Mapping an urban ecosystem service: quantifying above-ground carbon storage at a city-wide scale. Journal of Applied Ecology, [S.L.], v. 48, n. 5, p. 1125-1134, 11 jul. 2011. Wiley. http://dx.doi.org/10.1111/ j.1365-2664.2011.02021.x

GEHL, Jan. Cidades para pessoas. 2ed. São Paulo, Perspectiva, 2013.

GILCHRIST, K. Promoting wellbeing through environment: the role of urban forestry Forestry Commission UK, 2015. Disponível em: http://www.forestry.gov.uk/pdf/Trees-people-and-the-buit-environment_Gilchrist.pdf/\$FILE/Treespeople-and-the-buit-environment_Gilchrist.pdf Acesso em outubro/2020

GRANDE-ORTIZ et al. Methods of tree appraisal: a review of their features and application possibilities. Arboriculture \& Urban Forestry, v. 38, n. 4, p. 130-140, 2012.

HARDER, I. C. F. et al. Índices de área verde e cobertura vegetal para as praças do Município de Vinhedo, SP. Revista Árvore, Viçosa, v. 30, n. 2, p. 277-282, 2006.

JACOBS, Jane. The Death and Life of Great American Cities. Random House, 1961. São Paulo: Martins Fontes, 2000.

KLING, S. A própria cidade é o problema? Journal of Urban History, Chicago Tribune, Boston Globe, 2020.

LATOUCHE, Serge. Pequeno tratado do decrescimento sereno. Trad. Claudia Berliner. São Paulo: WMF Martins Fontes, 2009.

LEFEBVRE, Henri. Prefácio: a produção do espaço. Estudos Avançados, [S.L.], v. 27, n. 79, p. 123-132, 2013. FapUNIFESP (SciELO). http://dx.doi.org/10.1590/s0103-40142013000300009

MACEDO, Silvio Soares. SAKATA, Francine Gramacho. Parques urbanos no Brasil. 3. ed. São Paulo, EDUSP, 2010.

NOWAK, David J.; DWYER, John F. Understanding the Benefits and Costs of Urban Forest Ecosystems. Handbook Of Urban And Community Forestry In The Northeast, [S.L.], p. 11-25, 2000. Springer US. http://dx.doi.org/10.1007/9781-4615-4191-2_2.

OLMSTED, Frederick Law. Public Parks and The Enlargement of Towns. Cambridge. The Riverside Press. 1870.

OLMSTED, Frederick Law. Civilizing American Cities: Writings on City Landscapes. Perseus Books Group, 1997. 
ONU, Organização das Nações Unidas. HABITAT III. Documentos temáticos da Habitat III Espaços Públicos, Quito, 2016. Disponível em: <http://habitat3.org/wp-content/uploads/11-Espa\%C3\%A7o-P\%C3\%BAblico_final.pdf>Acesso em setembro/2015.

PAULEIT, Stephan; DUHME, Friedrich. Assessing the environmental performance of land cover types for urban planning. Landscape and Urban Planning, [S.L.], v. 52, n. 1, p. 1-20, nov. 2000. Elsevier BV. http://dx.doi.org/10.1016/ s0169-2046(00)00109-2

SÃO PAULO (cidade). Lei n 14.223, de 26 de setembro de 2006. São Paulo, 2006. Disponível em: <https://bit.ly/2FjBc4W> Acesso em outubro/2020.

SÃO PAULO (cidade). Secretaria Municipal do Verde e do Meio Ambiente. Tabela de cobertura vegetal por habitante (m2/hab.). São Paulo, 2012. Disponível em: <http://www.prefeitura.sp.gov.br/cidade/secretarias/upload/planejamento/Verde\%2010_2013.xls> Acesso em novembro/2020.

SÃO PAULO (cidade). Lei n 16.050, de 31 de julho de 2014. São Paulo, 2014. Disponível em: <https://gestaourbana. prefeitura.sp.gov.br/arquivos/PDE-Suplemento-DOC/PDE_SUPLEMENTO-DOC.pdf>Acesso em novembro/2020.

SÃO PAULO (cidade). Decreto ${ }^{\circ}$ 57.086, de 24 de junho de 2016. São Paulo, 2016. Disponível em: <http://legislacao. prefeitura.sp.gov.br/leis/decreto-57086-16> Acesso em outubro/2020

SÃO PAULO (cidade). Plano Municipal de Conservação e Recuperação da Mata Atlântica (PMMA). São Paulo, 2017. Disponível em: <http://www.prefeitura.sp.gov.br/cidade/secretarias/upload/PMMA_final_8_jan\%20ok.pdf> Acesso em outubro/2020.

SÃO PAULO (cidade). Secretaria Municipal do Verde e do Meio Ambiente. Cobertura Vegetal-Ranking Relativo, São Paulo, 2020a.

SÃO PAULO (cidade). Portal Geosampa. Mapeamento da Cobertura Vegetal. São Paulo, 2020b. Disponível em: <http:// geosampa.prefeitura.sp.gov.br/PaginasPublicas/_SBC.aspx> Acesso em outubro/2020

SÃO PAULO (cidade). Decreto n 57.583, de 23 de janeiro de 2017. Disponível em: <https://www. prefeitura.sp.gov.br/ cidade/secretarias/subprefeituras/vila_mariana/menu/index.php?p=87625>Acesso em novembro/2020.

SÃO PAULO (cidade). Secretaria Municipal do Verde e do Meio Ambiente. Protocolo para abertura dos parques municipais. São Paulo, 2020c. Disponível em: <https://www.prefeitura.sp.gov.br/cidade/secretarias/meio_ambiente/ parques/programacao/index.php?p=300241> Acesso em outubro/2020.

SÃO PAULO (cidade). Portal Secretaria Municipal de Educação. Centros Educacionais Unificados - CEUs. São Paulo, 2020d. Disponível em: <https://educacao.sme.prefeitura.sp.gov.br/centros-educacionais-unificados-ceus/> Acesso em outubro/2020.

SILVA, Leonardo. Subsídios para Formulação de uma Política para Áreas Verdes no Município de São Paulo. Em: A Questão Ambiental Urbana: Cidade de São Paulo. São Paulo: SVMA, pp. 425-449, 1993.

SILVA, Jarbas Barbosa da; BARROS, Marilisa Berti Azevedo. Epidemiologia e desigualdade: notas sobre a teoria e a história. Revista Panamericana de Salud Pública, Washington, v. 6, n. 12, p. 375-383, 2002.

TAKANO, T. Urban residential environments and senior citizens' longevity in megacity areas: the importance of walkable green spaces. Journal Of Epidemiology \& Community Health, [S.L.], v. 56, n. 12, p. 913-918, 1 dez. 2002. BMJ. http://dx.doi.org/10.1136/jech.56.12.913.

TEEB, The Economics of Ecosystems and Biodiversity. TEEB Manual for Cities Ecosystems Services in Urban Management. United Nations Environment Programme. 2011. Disponível em: www.teebweb.org.

THOMPSON, Catharine et al. Mitigating Stress and Supporting Health in Deprived Urban Communities: the importance of green space and the social environment. International Journal Of Environmental Research And Public Health, [S.L.], v. 13, n. 4, p. 440-445, 22 abr. 2016. MDPI AG. http://dx.doi.org/10.3390/ijerph13040440.

XIMENES, Deize Sbarai Sanches; et al. Pesquisa Emoções Momentâneas: Comportamentos e Hábitos Cotidianos Pós-Pandemia. Centro de Síntese USP Cidades Globais do IEA, 2020.

WHYTE, William H. The Social Life of Small Urban Spaces. Washington, DC: Conservation Foundation, Project for Public Spaces Inc. 1980. 